\title{
Communications
}

2015; 3(3): 63-70

Published online August 10, 2015 (http://www.sciencepublishinggroup.com/j/com)

doi: $10.11648 /$ j.com.20150303.12

ISSN: 2328-5966 (Print); ISSN: 2328-5923 (Online)

\section{Health Documentation in the Age of Information Systems}

\author{
Milena Marinič \\ Milena Marinič, Mater of Law. University Psychiatric Clinic Ljubljana, Ljubljana Polje Slovenia
}

Email address:

milena.marinic@psih-klinika.si

To cite this article:

Milena Marinič. Health Documentation in the Age of Information Systems. Communications. Vol. 3, No. 3, 2015, pp. 63-70. doi: $10.11648 /$ j.com.20150303.12

\begin{abstract}
Theoretical background: Health documentation is historically gained such an important legal document for the exercise of individual rights becomes increasingly important role. Domestic legislation but health records as legally significant collection of medical data and documents are not defined. Retention of important legal documents, therefore, it left to the operator. Methods: Using the prescriptive method will be determined and the laws governing the management of health documentation, safety and accessibility of health care documents. Based on descriptive methods will be described handling of health records within a provider of health treatment to exposed regulatory gaps in the protection of individual rights. Results: Through the analysis of the behavior of operators with health records, even after death, leaving the contractor will be the inductive reasoning carried out conclusions on the management of health records. Discussion and conclusions: Health data, in particular documents, which are to protect the individual rights relevant health records are not processed in modern technology. Health records are still kept manually, records of the documents in the collection are not allowing their disposal. Even the flow of health records in a medical institution is not defined. Manual and thus not trasparent data processing treatment consequently forms the basis for alienation of individual records or entire medical documentation and access by unauthorized persons. Due to the diversification of health data within a single controller comes to redundancy investigations, which increases costs and unnecessary divergence of time adequate medical treatment.
\end{abstract}

Keywords: Health Records, Security, Dispersion Data

\section{Introduction}

Medical documentation has since its beginnings in ancient Egypt 3000 years BC very varied. Even the ancient Greeks were writing the symptoms and treatments. After the year 1750 were in European hospitals to develop a systematic and objective records of the disease. The expansion of science means the maximum value of accurate health records, which are the sixteenth century has proceeded in a book called Sodbabook cases, following the example of the legal profession. Known Sodbabooks authors Forman-a and Napier's therefore considered the predecessor of modern health documentation. ${ }^{1}$ Keeping medical documentation in the late nineteenth century meant a doctor the possibility of analyzing the data. The need for systematic collection of data is dictated by hospitals to keep medical records; even if the operators did not have the standards of patient information should be collected. Individual doctors are writing the data in its own way, making the comparison of results and verifiable practically impossible or at least difficult. Beginning of the

1 History of medical record-keeping, 2011 twentieth century has brought in the hospital expansion of education, which has increased the need for standardizing health records. ${ }^{2}$ In parallel with education in the health care began the research for which the health record often basic matter. Operators of health documentation but still do not have specific detailed legal frameworks for health records management.

The purpose of health documentation is therefore in the history of mankind, as well as in the history of the document itself is changing. Health documentation is a much wider concept than the older concept of medical documentation as the latter records only doctor. ${ }^{3}$ Legal otherwise acting physician as the sole person responsible for medical records, but in practice in many institutions is only one of the creators of the records, because the paperwork effectively manage health Administrator or in the private sector nurses. The legal basis for the management of health records is Article 50 of the Law on doctors, which imposes a duty doctor keeping documentation on health status and treatment of the patient

2 BANNER Olivia, 2012

3 Creators health records, are doctors, nurses, social workers, physiotherapists, psychologists and others in the private and public health care facilities 
and other records in accordance with a special law. ${ }^{4}$

\section{The Importance of Health Records}

Clinical documentation is an important legal document giving rise to the state of health or disease, designed and health treatment, resulting in judicial processes is often the only source of evidence.

The awareness that the human body is the most intimate area of human privacy, ${ }^{5}$ leads to the conclusion that contain records in health documentation maximum details of the human body and the most sensitive data. With the creation of the legal significance of health records is a need for targeted management of health records. The first codification of this important collection of legal documents suggested Weed 1968. ${ }^{6}$ Later, many authors have created criteria required volume of the contents of what was on the meaning of information. The legal relevance of the information is so varied extent necessary forms and medical records. ${ }^{7}$ Today's health records, according to Flis most important cornerstone in the process of health treatment. ${ }^{8}$ Therefore, it is in countries with well-protected human rights conduct health documentation specifically defined by law. Flis health records separates the primary document that was created by direct contact between doctor and patient and a secondary document is a product of the analysis of multiple primary documents. In addition to these two appear in the collection as a tertiary document, which represent all the findings and documents of other artists, which relate to the health of an individual. In conjunction with the health records are becoming increasingly important, with legal ethical point of view, accurate records in health documentation, which increases the traceability management controls. Wellmanaged health documentation is exemplary doctor and his diligence at work. In addition, the foundation of good treatment and legal certainty for patients and health care treatment. ${ }^{9}$ Chronologically guided accurate records are an important indicator of the course of events, which gives medical documentation a big role in forensic medicine. ${ }^{10}$

\section{Databases}

The current law on databases in the health sector is already fourteen years old and governs only the database, but not the processing of documents of health information. Plating said the law left the implementing regulations, which have never been accepted. Databases Act in the area of healthcare (ZZPPZ) of 2000 governs only the database and does not regulate the content of collections, nor regulates the handling

4 Medical Services Act (official consolidated text) (ZZdrS-UPB3), Official Gazette of RS, no. 72/2006 dated 11. 7. 2006. Page. 7657th

5 LEACH Philip. Opinion of the Court, 2005: 315

6 WEED Lawrence L., 1968

7 MC WHINNEY Ian. 1989: 378

8 FLIS Vojko,.1999:233

9 MC WHINNEY Ian. 1989: 377

10 KERSNIK Janko. 1994:4 procedures. The term "the establishment of documentation" is not legally defined. ${ }^{11}$ The legislator must define the first record as the creation date health records, irrespective of the subsequent supplements. ${ }^{12}$ The date of the last record in the health documentation is unpredictable, as such term is reliable only the date of death of the patient. From the present legal provisions it shows that the Law on databases in the health nor his proposal did not eliminate the current legal vacuum by other applicable laws already allowed; as regards access to health data within the controller, and the handling of copies, better Kaut in the current archive, retention time and milestones occurrence archives, collections surrender medical records after the termination of activities as well as the transfer of health data to other operators (insurance companies, social work centers) and destruction. Census disease onset in the inpatient medical treatment and basic medical documentation which should be collected all the medical data on a particular person. What falls under the law applicable to the basic medical documentation from the law itself is not clear. The dilemma arises because different specific retention period (10 and 15 years after the death of the person to which it relates) for those two databases (ZZPPZ). On the basis of a literal interpretation, I conclude that it is in the inventory of diseases for health documentation generated in hospitals for basic health documentation in general clinics. The proposal for a new law on databases in the health sector shows that despite modern technology in the possession of organizations delivering health care business of health information in the Republic of Slovenia remain written on paper. The paper format of health records is a reality; both in connection with the collection and storage, as well as the transfer from one to another contractor. In doing so, however, the bill paper form assessed as successful functioning, which in reality does not hold, at least in the vast majority does. ${ }^{13}$ Out of inaccurate statements it can be inferred from the legislature poor knowledge of the facts. The electronic form processing and data exchange is well regulated financial part of health services, electronic records of health services is practically nonexistent. The exchange of health data between different providers takes place only on paper. In recent years, appearing only electronic records of computer examinations ${ }^{14}$ by the operator to removable disk also handed over to the patient. Connoisseurs of the situation in the health sector are to a draft law presented an opinion on the highly unregulated

11 Whether this is the first record in the health documentation of the individual and thus the formation of documentation. What happens when an individual's health status information to emerge sporadically with a spacing of several years (including 10 and over)

12 In the University Psychiatric Clinic Ljubljana returning patients as more than 30 years after the last medical treatment

13 It is the absence of a record of medical records. There is no single document therefore not possible to determine the storage periods. Data transfer between the operators is slow, allowing loss, theft, modification of data, including unauthorized pairing, with each stage of processing are not documented and traceability insights practically impossible.

14 These are the videos RTG, CT, MRI, and the like, which on the CD medium gets into the hands of the patient 
recording and documenting facts and data. The law must take, based on the principle of a general right to protection of personal health information, ensure the individual right to privacy and confidentiality as inherent in being informed and influenced by an individual on their treatment. One is based on this principle, the right to determine the persons who may not be familiar with his health data, this information should be accessible to the operator via computer applications and health insurance cards. The legislature could set this work did not materialize.

Based on the draft law on databases in the health sector is the task of the competent ministry to prepare methodological guidelines that specifically define common definitions and classifications, registers (classification of documents) for managing personal databases and define a safe processing of personal data in the health. ${ }^{15}$ Draft law defines the processing of personal data patients with the Central Registry data. ${ }^{16}$ From the wording of ZZPVZ-1 shows that, according to the legislature's statutory suitable protected mode access and exchange health records, upon written request of the patient through the use of a qualified certificate. ${ }^{17}$ The proposed content of the bill below governed access to medical records, protection using cryptographic methods. In addition to all the bill provides for the provision of funds from the state budget for implementation of the regulatory, statistical and research at the national level for the establishment and management of collections, but does not include basic medical documentation, which on the basis of a teleological interpretation leads to the conclusion that the legislature basic health documentation of less importance and will receive less protection, despite the fact that combining documents of various health treatments and therefore contain a maximum of health data.

\section{The Processing of Health Data}

The Law on Protection of Personal Data (ZVOP-1-UPB1) health information among sensitive personal information. Therefore, for the transmission of sensitive data controller is obliged, under the ZVOP-1 UPB1, for each intervention to ensure that it is subsequently possible to determine:

- which personal data were transmitted,

- whom,

- ever,

15 The Ministry of Health was invited to participate as the author of this work, along with other experts, connoisseurs of the classification of documents and the processing of medical documentation in order to prepare a single klasifikacijkega plan is the replacement of the government and economic situation to work a bit frustrated. In 2014 he created only recommended classification plan for health institutions, but does not mean a unifying description of the documents.

16 Central Register of patient data (hereinafter: CRPP) is intitut that all providers of health care in the Republic of Slovenia provides insight into the personal health information where this is necessary for the provision of emergency medical assistance. Insight into this database is also admissible provider of emergency medical treatments abroad for the needs of emergency medical aid to individuals državjanom RS abroad. Where it is not for medical emergencies, processing the collected podatkv permitted only with the consent of the patient

17 ZZPVZ-1
- on what legal basis.

All this information has the right to require an individual to the period when the statutory protection of their rights due to unauthorized disclosures of personal data even possible. ${ }^{18}$ Personal data of the deceased may be based on the provisions of Article 23 of the controller to a hereditary beneficiaries and users who are processing such data, authorized by law. The data controller is obliged under Article 26 of the ZVOP1-UPB1 set up for each database, which also runs a catalog of data which that database contains. For such a catalog in conjunction with health documentation is necessary unification of forms that represent its content. Such standardization of forms to represent it easier to compare data among themselves, as well as a well-defined retention period of each form.

\section{Acquaintance with Data}

After the death of the individual is 10 years of age is entitled to store health information manager, this is a health treatment. For this period, the statutory protection of these data provides the ZVOP- 1UPB-1. ZVOP-1-UPB-1 in connection with the protection of personal data also provides pairing heirs after death. Request heirs or other persons to personal data of the deceased from 23 Art. ZVOP-1-UPB-1 be refused on the basis of written or oral statements which put the patient before his death in the presence of two witnesses, the prohibition of pairings, which has brought a relatively new ZPacP. This document is an integral part of health documentation necessary to convert in electronic format, including the possibility of loss of the original. Computer application must be able to warn the operator available for the patient after his death. In practice, however, operators manually enter data on deaths in the electronic patient record. Ten-year retention period for health records after the death of the individual must follow the elimination and destruction of documents or the selection and transfer in the archive. Due to the fact that health data are processed as archival material, this documentary material processed by ZVDAGA. ${ }^{19}$ The Act, however privacy issues for health records not covered because it also does not pay any special attention. Even within the archival law is therefore a need for greater protection of health care data.

Good practice of protecting health records arising from a legal act of the California Legal medical record standard. The said act considered medical documentation as a hybrid record, since it is located in separate locations as well as in paper and partly electronically. The regulation provides, inter alia, that the necessary health records to identify each page of a multipage document with full name and surname of the patient and uniform number of the health card. Implementation of this provision prevents its voluntary or involuntary replacement parts health records of different

185 para. Article 24 ZZPVZ-1 imposes a duty manager with data recording and facilitate pairings

19 The law on the protection of documents and archives and the archives 
people. It is therefore not permitted from health records photocopied each page separately, or send by fax. Access to health information is essential to define in operational terms; that is, in everyday use. Even in this part of the Legal medical record standard foreseen limits and, through a review committee, quality management and documenting insights. The transparency of the processing of health data representing the recording requirements to view or obtain photocopies of the information system. This rule should also follow each issue health records from the archive. Such records are therefore also enables transparent and immediate response to an individual request for the list of all those who were familiar with health data. That provision also regulates the traceability of insights, making each health worker can access the information system using only their single identification. Preservation of health records is very important but neglected area in the Slovenian legal system, it is specially well-governed legal-health record standard. Health documentation must be the protection of privacy at all times kept in a room and under conditions which prevent loss, destruction, alteration. Even more important for the security of documents in the health documentation, the obligation to keep the chronology of health documents from the database is not allowed to delete anything, nor remove the documents. In order to avoid possible errors due to illegible colorful and therefore misinterpretation of the text regulation imposes obligations on the clarity and legibility of the recordings of the author of the record. ${ }^{20}$ In the case of electronically controlled health records because printed contents provided clarity records. Also, the threat of possible errors due to illegibility is a big reason for keeping medical records, including prescriptions electronically. Comparison with that regulation indicates that Slovenian legislation on health documentation provides only that the doctor on the basis of 50.čl. the Medical Services Act obliged to keep records of the health status and other records provided for by law. ${ }^{21}$ The Act, nor the other does not give detailed instructions for managing health records and privacy protection in it.

Therefore, from the view of the laws of California conclude the necessity of a well-ordered an implementing regulation in the Slovenian legislation. Tracking insights is an important provision on the use of professional cards. In Slovenian law is prohibited sharing of professional cards denial traceability insights. Even removing out health records from the premises of the operator in Slovenian law is not prohibited, nor defined as a felony, which represents one of the greatest threats to privacy. Emergency contents of records and manner of handling health records constitutes a legal vacuum in Slovenian law. Legally it is not certain a safe place where they can use this. ${ }^{22}$ Above all, health records in

20 Thus, the medical documentation California Legal Medical Record Standards Policy No. 9420th Chapter: III Contents of point C on the page 5

21 Medical Practitioners Act,2006 and any changes

22 Part of the medical documentation required for the preparation of therapies, this is the sheet temperature must always be accessible to nursing staff, inventory disease should remain always in one room available as a reading room material. domestic law does not provide authentication, ${ }^{23}$ so the future legislation to exclude erroneous recording due to poor legibility of the mandatory direct inputting data into electronic form. Part of the health documentation required for the preparation of therapy, it's thermal sheet must always be available to nursing staff, inventory disease should remain always in one room available as a reading room material. ${ }^{24}$ The volume of health records is not defined, therefore, it raises the question what constitutes health records and legal importance, to which partially respond to justify decisions of the courts below.

In foreign case law in relation to Clark Boyd v. US notes that the health documentation the health card, which allows you to read health records and electronic health record, unpublished. ${ }^{25}$ The need for a holistic approach to health documentation also notes the Information Commissioner RS, requiring records of documents within the health records, which reduces the possibility of abuse. ${ }^{26}$ The traceability process hearing only stems from the integrity health records, which is legally very important collection. It contains all legally relevant facts as a basis for judicial review of the conduct of medical staff and the development of diseases such as damage to health. Greater legal value of records ensures their chronological and contextual accuracy of records. ${ }^{27}$ Changes in health status, causes and consequences of the most transparent in the records in medical documentation. Therefore, in particular, they serve to clarify the appropriateness of treatment which may be an indication of the cause of death, which confirms the interpretation of the judicial decisions of the Supreme Court of Alabama, in the case of Ex parte Northwest Alabama Mental Health Center. Skip, Newman. Judicial experts are deciding in a lot of help in addition to doctor records the detailed records of nurses within the health documentation. Even from domestic

\footnotetext{
23 Records in paper format resulting in three ways: the doctor himself manually recorded on paper, the doctor notes Administrator overwrites or doctor dictated text. Dictate directly to the admin, more modern and more economical in the dictation recorder which subsequently overwrite administrator.

24 Legal certainty also provide writing all the records on the Journal temperature. In capital letters, which reduces the possibility of errors

25 Clark E. David.2010

26 As confirmed by the reasoning of the decision of the Information Commissioner of the Republic of Slovenia 0710-66 IP / 2011 / 13th The patient was in its appeal Office of the Information Commissioner requested from the operator database also documents that medical records are never localities. The traceability of this fact to detailed chronological list of documents making up the medical records. Description of documents may be finding relevant information is problematic, because the operator can not know with certainty what data and from which the document comes as the diameter of the appointment for the same document: discharge letter / completion of treatment / discharge summary or opinion / report.

27 The great importance of accurate records is also confirmed by the ECtHR in the grounds of the decision in the case McGlinchey and others v. The United Kingdom. Ms McGlinchey was due to theft sentenced to a term of imprisonment of four months from 7 December 1998. As uživalka drugs in prison experienced withdrawal syndrome. She was examined by doctors in the welfare, drop in blood pressure, weight loss and vomiting, which was also recorded in the medical documentation. The Court found that it was not been given adequate medical care and even elements of inhuman and degrading treatment. Relatives, the court awarded damages
} 
case law is clear that the health documentation legally significant document in legal proceedings for damages and therefore for judicial review, in addition to accurate health records, an important organization and management of precise chronological history of health and disease. ${ }^{28}$

I note that there is no uniform set how long it is necessary to protect a specific type of health documentation and when if ever - to destroy it. Undefined content and the absence of a list of the contents of health documentation represents the unregulated area. It is therefore considered quod non est and ACTIS, non est and mundo (lat.) Or "That which is not in the scriptures, this is not the world". Definiranost documents which are an integral part of health documentation constitutes a legal problem due to non-uniform designations at the national level. Handling of documentary material must be uniform in future legislation at national level along the lines of the Anglo-Saxon legal system. Despite the age of computerization is the increasing importance of health records for the enforcement of individual rights remains essential legal protection manually kept records, because health records are still largely kept manually. Selected manually controlled health records also presents archival documentary material. Availability of such archival documents would be provided by converting the computer form, while the biggest obstacle funding.

Health records generated from birth until the death of the person to whom it relates. The history of the disease also contains records of other family members. ${ }^{29}$ The records of the health status of individuals affect the good name and dignity of the individual and indirectly also to the dignity and reputation of his descendants, the closest members and close relatives. Health documentation records represent various health professionals in paper or electronic form, images in digital form, photography, digital images fruit, computerized tests, as well as a letter or health records content. Under the current law acting as a doctor only person responsible for medical records, but in practice the health records of governing and taking care of the storage of health administrators and nurses. This goes for the disposal of various documents in the shared folder, with no track record of production and the arrival of the document. Such a chronological record of health data represents exemplary guidance and legal certainty for the operator and patient because the only available and authentic documents and records can be evidence basis for the exercise of individual rights. Health records about an individual, even within a single institution, run by various experts. The method of keeping, storage, accessibility and integration but is not

28 As confirmed by the justification for the decision of the Higher Court in Ljubljana in case I Cp 2835/2009. History of the record narration patient or relatives when receiving a patient is formed exclusively on the information provided by the injured person or witness. These are the patients description of the event, a doctor may not alter or otherwise transformed. The application form of an accident is not an integral part of medical documentation and after four years of ruin. The Court examined whether there was deliberate destruction of notification of an accident to cover up this alleged medical error

29 These are the same symptoms of other persons in the family legally defined, allowing excessive availability of unauthorized, disposals of individual files or entire documents. Legal undefined area is also storage, security and accessibility of health records after the death of the private health-care providers or creator records, both private doctors and experts.

\section{Ongoing Collection of Health Records}

Archive current collections medical documentation indicates a high turnover of documents and legally undefined behavior. The current collection is therefore a retention of documents necessary for the topical treatment of the individual.

In Slovenia, the health documentation that is required for medical treatment, more or less accessible to health professionals left the department and their moral qualities. ${ }^{30}$ Due to the abuse and because legume corrector usus (lat.) Or laws corrects application, the prospective law to provide that health documentation in paper form is not available in the department.

Health records, in practice, collected in so-called Ongoing collection after the death of a person could be kept in the permanent collection of documents and archives. Access and handling of liquid collection of health records, the Act should be regulated at the national level, because it is currently in compliance with the ZVOP-1-UPB1 each operator shall be governed by their own; however, other laws do not regulate this area. Health documentation is required for the work of a doctor at any readmission of a patient in an institution ${ }^{31}$ or is it just a yes magna est vis consuetudinis (lat.) or a large force of habit. ${ }^{32}$ The need for access to medical records, the paper forms 24 hours a day, are in the age of digitization of most health information, opinions differ even within a single controller. ${ }^{33}$ Traps for violation of privacy will fall at a time when the contractor will only use the computerized database of health information and establish secure access to handheld files. With insight into the papier health records medical professionals to avoid traceability. Secure processing of medical data is based only on the so-called internal traceability, upon written request to obtain documents from any current or permanent archive and recording processes in an electronic database. Records of such requests is the basis of the data with which an individual will be informed about the transmission of his health data. The availability of a

30 Writing the narrative of the patient, the healthcare professional, accessible 24 hours. The difference is in the medical documentation of forensic patients where the internal rules on the basis of limited availability. Health information staff serve as inspiration for writing the book which describe the stories of patients, as in the book Pavlica. Pavlič Natalija middle nurse in a mental institution October 2012 in Pasadena, published a book entitled Pitfalls of perception which describes the narrative of patients treated in a psychiatric hospital.

31 Admissions of patients in all hospitals are not designed, but rather take place in the afternoon and at night

32 Each hospitalization is a unique event therefore requires a comprehensive and specific assessment

33 All health records are records in electronic form, but it is still guided paper medical records in which are located the findings and opinions of other experts 
larger number of employees to the current collection of documents, namely, poses a major risk of abuse. ${ }^{34}$ In Slovenia, due to the archaic method of processing health documentation is still prolonging health treatment time, while redundancy of the investigations, loss and theft of documents. Double-guided health records do not provide integrity, while insights into hand-guided or paper health documentation does not record.

\section{Photocopying Health Records}

Health records are the swing and the availability of photocopiers and mass unattended photocopied both internal as external users. This phase of the processing of health data is completely uncontrolled, non-transparent; so also the owner of the health data inaccessible information. ZVOP-1UPB1 this area not specifically governed. ${ }^{35}$ In the absence of substantive regulation of photocopying health records through'll review the rules governing the Banquet, sought to find legal protection of privacy in the photocopying health records.

Law of Personal Identity Card $^{36}$ which allows financial institutions to copy the identity card imposes a duty to any such photocopy stamped and annotation purpose of copying, which prevents further material copy of that copy. On the basis of a teleological interpretation to the conclusion that greater intervention from the photocopies of personal data is a scan of greater possibilities for abuse. ${ }^{37}$ Basis for the adoption of technical measures and the establishment of registers of processing for data protection in domestic law, Regulation (EC) No. 45/2001 of the European Parliament and the Council. This is the foundation handling photocopies of documents in administrative operations provided for by Article 136 of Decree on Administrative Operations. ${ }^{38}$ If, however, a good practice leaflet Looking for work with classified information of NATO and the EU concluded that the separation of documents and labeling classification on the

34 Healthcare worker with medical treatment did not participate had no legitimate right of access to medical records, and its a well in the morning was not available. In practice, however, the power of the superior misused for unauthorized access to the health records in the afternoons. Such access shall therefore not been recorded. Transparency access to medical records is guaranteed only if each issue of documentation is kept arhivarka upon written request. Consistency written request to each issue of medical documentation, in the event of hospitalization, from the archives of the author introduced in the Psychiatric Clinic beloved and thereby contribute to greater transparency information. This document constitutes the guard, as the applicant must write the purpose of the use of documentary material (such as, for example, of the person), avoiding claims of unjustified personal reasons. Using medical records from the current and permanent collections of the principle of the reading room significantly increased the security of health data, prevent misuse and loss of documents.

35 ZVOP-1-UPB1-1 5 section 1 para. 24.člena otherwise requires the operator of a duty of recording processing of the name of the person who processed the data and the reason of the processing of personal data

36 The Law on Personal Identity official consolidated text (ZOIzk-UPB2) Official Gazette of RS, no. 71/2008

37 The Law on Personal Identity in 6 para. Article 3 explicitly states a ban on the storage of the scanned ID cards

38 Decree on administrative operations Official Gazette of RS, no. 20/2005 of 3 . 3. 2005 basis of which rules are also provided photocopies of such documents. ${ }^{39}$

Photocopying documents in general in the $\mathrm{EU}^{40}$, in particular health documentation in the Slovenian legal space in the current legislation is not regulated. In conjunction with photocopying medical dokumenatcije note odstnost complete control. The individual has no influence on who, how many and for what purpose will be copied documents containing his medical records, since the paper medical documentation managers do not keep records. Many patients are entitled to acquaint themselves with the facts, who was familiar with their medical data are not familiar with. Therefore, it is true the saying "ignorantia iuris Nocetti." Or "Ignorance of the law is. The patient, in accordance with the ZVOP-1 right to know to whom and for what purpose were his medical data is transmitted, which the operator is obliged to keep records. ${ }^{41}$ The rights of individuals to be informed about who was familiar with its physical records in medical documentation in paper form Slovenian legislation is not being implemented.

\section{Central Archive}

In the Slovenian health institutions, the health records shall be kept in paper form. Therefore, the central archive assume the role of guardian of the archives also that this will be complete and available to the beneficiaries. ${ }^{42}$ Keeping documents in electronic form would mean the immediate availability (no archivist), connectivity of various outpatient records one health institution, which reduces the time of inspection to diagnosis and treatment, as well as significantly increase the rational use of public money. It is therefore the task of the central archive in addition to preservation of documents:

- conversion of documents into electronic form combine the health records

- record of all requests

- facilitating access to the patient, relatives and researchers.

All documents in electronic form would be so accessible to the beneficiaries as a reading room materials via a computer in the reading room of the archive. Such accessibility of the material substantially prevents abuse. Electronic logging of requests, issuing documentation in its original form, or photocopies of court experts, researchers and other beneficiaries also allows you to record the repayment of such documents or photocopies of repayment by the operator and then destroyed. The information system also generates a list of people who were familiar with health

39 The indications confirming instructions for working with classified information of NATO and the European Union

40 From the reasoning of the decision of the ECtHR Amann in Swicherland follows confirmation that the path of photocopies is not clear, also individual has no legal basis to prohibit the photocopying of documents with its data, for the purposes of court, much less decision who and how will the nutrients documentary material

41 In accordance with paragraph 22.3 Law on Protection of Personal Data 
data. Currently the operators of this right does not provide patients in its entirety, since the absence of records incomplete data, patient privacy poorly protected from uncontrolled access to the database. ${ }^{43}$ In dealing with the holders of health data should be subject to non abundans cautela do not want (lat.) Or a man is never too careful.

\section{Health Records After Dissolution Manager}

Right of access to health records after the death of a private physician or the interruption of work in the RS with operators of private law more difficult to achieve. Slovenian law requires otherwise the Contractor of medical treatment of private law at the termination of private law duty of all medical records of patients in accordance with the provisions 40.čl. The Medical Services Act (ZZdrS-UPB3) give, with the consent of the Medical Chamber to another operator. The Medical Chamber is required to determine the administrator's medical files, if the operator fails to do so itself. Due to the fact that private medical clinics in private premises or premises which the operator has hired the right manager of health records, in accordance with Article 41 of the same Act, in the event of the death of a doctor to enter the premises of the clinic and take health records. ${ }^{44}$

I conclude that the legislator has provided hand-circuit collection. At the private hardware and software it is therefore essential to define the legal transfer data electronically controlled. The management of health data after termination of the business best governed Switzerland, which in the current legislation specifically defines the scope of health documentation and the manner of management. It is also precisely regulates the handling of medical records on the death of the doctor or the death of a patient, which is important for patient privacy. ${ }^{45}$ The opposite of predictable treatment represents American law, especially Accountability Act, known as HIPAA, which provides illicit brokering of health data without the knowledge and consent of the patient. HIPAA provides otherwise protect the privacy of the patient to doctors, hospitals and pharmacies, but does not define the conduct sufficiently precise to allow abuse.From the above domestic law (ZZdrS-UPB3) shows that monitoring the implementation of legal provisions belonging to the ministry, but for non-compliance with the provisions of Articles 40 and 41. Article does not provided any criminal sanctions; not the health worker who has ceased to practice, nor does it impose criminal liability Chamber of the targets are not achieved its statutory duties. The responsibilities of heirs who have the medical records after the death of the contractor, the law does not speak. Legally insufficiently

43 Because of staffing reasons, the absence of an archivist in the afternoon and night time is allowed access during this time medical staff The fact that the spaces for archiving detached from the others and in this present time in prison only a few people increase the risk of misuse of health information

44 Medical Practitioners Act (ZZdrS)

45 Krušič Mate Zana The right to privacy in medicine, 2010: 152 defined handling of medical records after the termination of private practice provider can lead to dangerous treatment of sensitive health data. The accessibility of health records, private providers of healthcare davnosti in the applicable legislation remains unresolved. Denied access to health records, representing patient deprived of the possibility of exercising rights to adequate health treatment, compensation claims, pension and disability protection, employment rights, health insurance, maternity care and child access. Adequate protection of health records after the death of the Contractor or the termination of private law is also important for the protection of health data so the forthcoming legislation on health documentation to regulate this area of provision of individual rights.

\section{Conclusion}

Health care their attention to caring for the patient, while leaving highly unregulated processing of medical data both from the standpoint of security, integrity, availability and connectivity; manual files, as well as electronic records. Data collection should serve the patient, which in the case of health data is not quite true. Electronically controlled health data from such media can also be printed, which would completely eliminate the uncontrolled reproduction and provide traceability in this part of the treatment. Health information is a political matter in all social systems, it is the social will depend on the adoption of a law that will dictate cheaper and more economical management of health records, it would also oversaw the operator discretion to illegal insights.

\section{References}

[1] BANNER Olivia. 2012 in the Medical Futures lab. Nov. 09.2012. URL:www.medicalfutureslab.org/2012/11/09/whatcan-the-history-of-medical-records-teach-us-aboutmeaningful-use-guest-blog-post-by-olivia-banner/:1.6.2014

[2] Clark E. David. Medical privacy at risk in Georgia,2010. URL: http://www.ajc.com/news/news/opinion/medical-privacy-atrisk-in-georgia/nQhZQ/13.6.2015

[3] FLIS Vojko. Medicine and pravo.1996,1998.1999: 233rd

[4] History of medical record-keeping, 2011. URL.http://www.magicandmedicine.hps.cam.ac.uk/onastrological-medicine/further-reading/history-of-medicalrecord-keeping.4.9.2014

[5] KERSNIK Janko. Problem-oriented documentation in general medicine. Medical views 1994; 33: 223-40.

[6] KRUŠIČ MATE Zana. The right to privacy in medicine. GV založba.Ljubljana, 2010.

[7] LEACH Philip. Taking a judgment to the European Court of Human Rights. Second edition. Oxford. 2005th

[8] MC Ian Whinney. R. Records and A texbook of Family Medicine, the 1989th 
[9] MC Ian Whinney. R. Records and A texbook of Family Medicine. Second edition. The Oxford University Press (MA P), New York, 1997.

[10] Proposal of the Law on databases in the health sector (ZZPVZ-1). http://www.mz.gov.si/fileadmin/mz.gov.si/pageuploads/javna razprava_2011/jr_zakon_o_evidencah_260811/zakon_o_evide ncah_jr_260811.pdf: 07.03.2014.

[11] Regulation on administrative operations. Official Gazette of RS, no. 20/2005 of 332005 th

[12] Instructions for work with classified information of NATO

[13] The Law on the protection of documents and archives and the archives (ZVDAGA). Official Gazette of RS, no. 30/2006 of $233,2006$.

[14] The judgment of the ECtHR McGlinchey and others v. The United Kingdom.Opr. No 50390/99. URL: http://hudoc.echr.coe.int/sites/eng/pages/search.aspx?i=00161058.:2.9.2014.
[15] The Judgment of the Higher Court in Ljubljana in case I Cp 2835/2009. URL: http://www.sodisce.si/znanje/sodna praksa/visja_sodisca/648 $66 /: 1.9 .2014$.

[16] Law on the protection of personal data. (ZVOP-1-UPB-1) Official Gazette of RS, no. 86/04 with subsequent monitoring. and supple.

[17] WEED Lawrence L. Medical Records That guide and teach And England Journal of Medicine, the 1968th

[18] The judgment of the ECtHR in Amann Swicherland ref. No. 27798/95. URL: http://hudoc.echr.coe.int/sites/eng/pages/search.aspx?i=00158497: 01/09/2014

[19] The Law on Personal Identity Card (ZOIzk-1) Official Gazette of RS, no. 35/2011 of 13 th 2011th

[20] The Law on Medical Services official consolidated text (ZZdrS-UPB3). Official Gazette of RS, no. 72/2006. 